\title{
Effect of Process Modes on Tangential Component of Cutting Force during Belt Rotary Grinding of Aluminium Alloy Blanks D 16
}

\author{
Tatiana Stadnik ${ }^{1, a^{*}}$, Denis Sidorov ${ }^{1, b}$, llyas Temindarov ${ }^{2, c}$ and \\ Pavel Novikov ${ }^{1, d}$
}

${ }^{1}$ Polytechnical Institute, Sevastopol State University, 33, Universitetskaya, Sevastopol, 299053, Russia

${ }^{2}$ Crimean Engineering and Pedagogical University named after Fevzi Yakubov, per. Uchebnyy, 8, 295015, Russia

atanya-stad@yandex.ru, bSidorov-sntu@yandex.ru, ctemindarov23@gmail.com, dPANovikov@sevsu.ru

\section{Keywords: Grinding, Abrasive Belt, Rotary Belt Grinding, Cutting Force}

\begin{abstract}
These days, in the manufacture of units and mechanisms of ships, aircraft and other technological machines, industrial robots, long-sized products from D 16 (Standart GOST-R) aluminum alloy are used, for the processing of which a complex for belt rotary grinding has been developed. The outcome measures of the rotary belt grinding process depend on the cutting forces generated during the processing process. According to cutting forces, process stability is diagnosed, values of surface roughness indices, temperatures and cutting modes are calculated according to displacement balance equation. The article is devoted to obtaining a mathematical model establishing the relationship between the tangential component of the cutting force and cutting modes during belt rotary grinding of D 16 aluminum alloy.
\end{abstract}

\section{Introduction}

In modern technology, in many industries such as aircraft engineering, instrument making, automotive, shipbuilding, etc., aluminum alloys are used to make parts. Aluminium alloys have high chemical activity and viscosity, which leads to the formation of growths on the tool [1]. D 16 (Standart GOST-R) aluminum alloy has gained widespread use. In view of its high lightness, strength and hardness, the alloy is used to make various metal rolled products.

Currently, in the manufacture of units and mechanisms of ships, aircraft and other technological machines, industrial robots use long-sized products from aluminum alloys, in particular from D 16 alloy. Long products include products made of rods, wire and tubular billets of rectilinear and curvilinear shape, which are used as guides of metal cutting machines, welding robots, conveyors.

Abrasive-diamond processing methods [2-10] are used for finishing a number of such articles. In the processing of such articles, there are a number of difficulties associated with the impossibility of rotating these parts during processing, especially in the case of curvilinear shaped articles. Therefore, for treatment of long axisymmetric non-rigid parts, where rotation of the machined part is impossible or difficult, such as rolled stock, pipes, straight and curvilinear wire with the most optimal machining scheme from the point of view of low surface roughness, a method of rotary belt grinding is proposed [11-14].

For the treatment of curvilinear (radius) blanks at the Department of Engineering Technology, Sevastopol State University, a complex for belt rotary grinding has been specially developed,

(c) (i) Content from this work may be used under the terms of the Creative Commons Attribution 3.0 license. Any further distribution of this work must maintain attribution to the author(s) and the title of the work, journal citation and DOI. Published under license by Materials Research Forum LLC. 
which consists of a belt rotary grinding device 1 and a device for feeding the radius blanks 2 (Fig. 1).

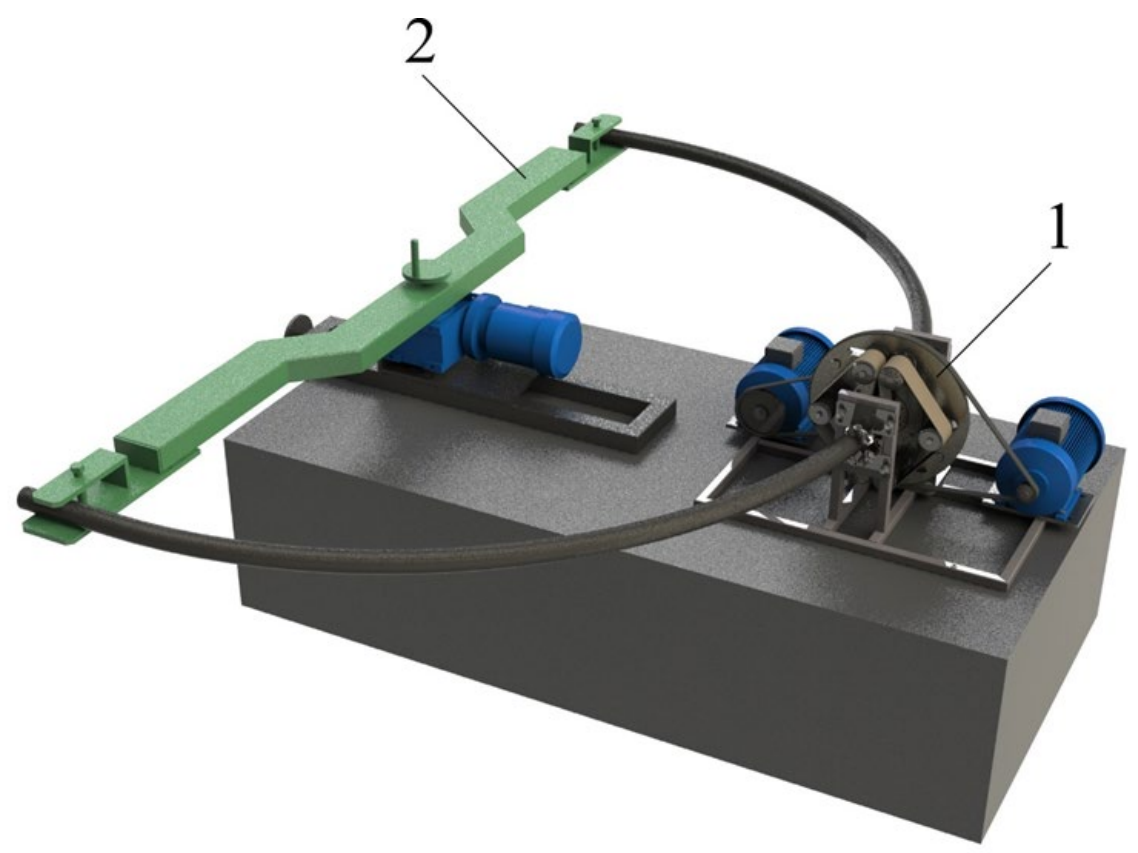

Fig. 1. Model of the complex for belt rotary grinding of radial billets.

The principle of operation of such a device is as follows: the radial blank is fixed in a rotary mechanism, the axis of rotation of which is installed from the axis of the belt grinding device at a distance equal to the radius of bending of the blank. The rotary mechanism with the blank in manual mode is set to the initial position - as close as possible to the edge of the blank. Rotation of the belt and the swivel mechanism is turned on. If it is necessary to move the workpiece back, reverse pendulum movement is activated.

It is known that the output of the belt rotary grinding process correlates with the cutting forces generated during the processing process. According to cutting forces, process stability is diagnosed, values of surface roughness indices and cutting modes are calculated according to displacement balance equation. According to the literature [15], the process of belt rotary grinding is significantly influenced by the grain and speed of the belt, as well as by the pressing force of the belt, which are suitably used as varying variable factors. On the basis of the above, the object of this work is to obtain a mathematical model of the tangential component of the cutting force depending on the speed of the belt, its grain size and the radial component of the cutting force in belt rotary grinding of D 16 aluminum alloy blanks.

\section{Results and discussion}

Experimental studies were conducted to build models. Studies were carried out on samples of round cross section, diameter $10-50 \mathrm{~mm}$, normal manufacturing accuracy, length $3000 \mathrm{~mm}$ ) from aluminum alloy D 16.

To measure cutting forces, dynamometric centers (front and rear) were used. They were equipped with wire-wound resistors (resistance sensors) between which the workpiece was fixed. Two dynamometer centers allow to record the cutting forces during the grinding process at any 
position of the grinding belt relative to the workpiece. Wire gauges, glued on the vertical planes of the front and rear centers, are connected in one bridge and are used to measure the force $P_{y}$ (Fig. 2). Sensors glued to the horizontal planes of both centers are used to measure the force $P_{z}$.

The measurement scheme includes dynamometer centers, an amplifier, and an analog-to-digital

a

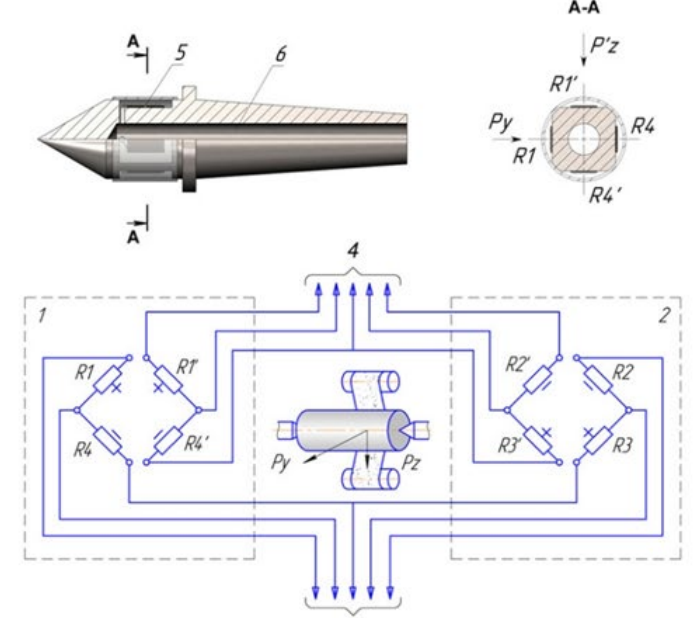

$\mathrm{b}$

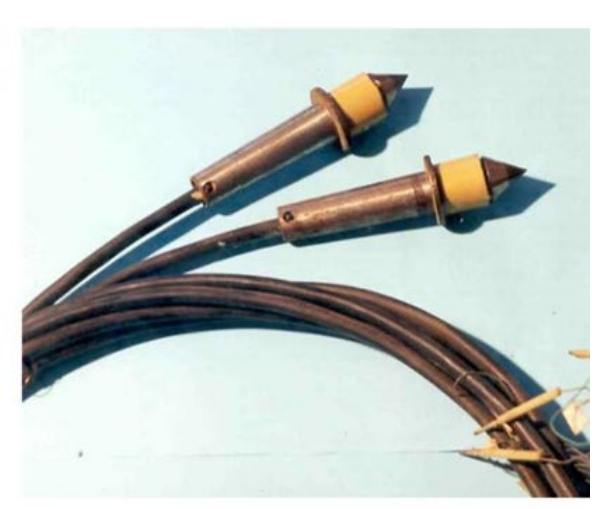

Fig. 2. Tenzometric Centers (a) - a scheme to include wire resistance sensors to measure the forces of $P_{y}$ and $P_{z}$. $(1$ - the front center; 2 - the rear center; 3 - wires to the device to measure the force of $P_{y}, 4$ - wires to the instrument to measure the force 5 -sensors; 6 - a hole for the output of wires); (b)-photography of the tensometric centers.

Converter ЛА-50USB (Russian production) connected to a personal computer using a wellknown technique. Calibration of strain centers was performed by static loading. The calibration scale was determined by the least squares approximation. The calibration graph was linear. The total error when using this method is $10 \%$. The longitudinal movement of the dynamometric centers, with the workpiece fixed between them, during the measurement is carried out along the guides on the bed by means of a gear rack and a stepping motor (Fig. 3).

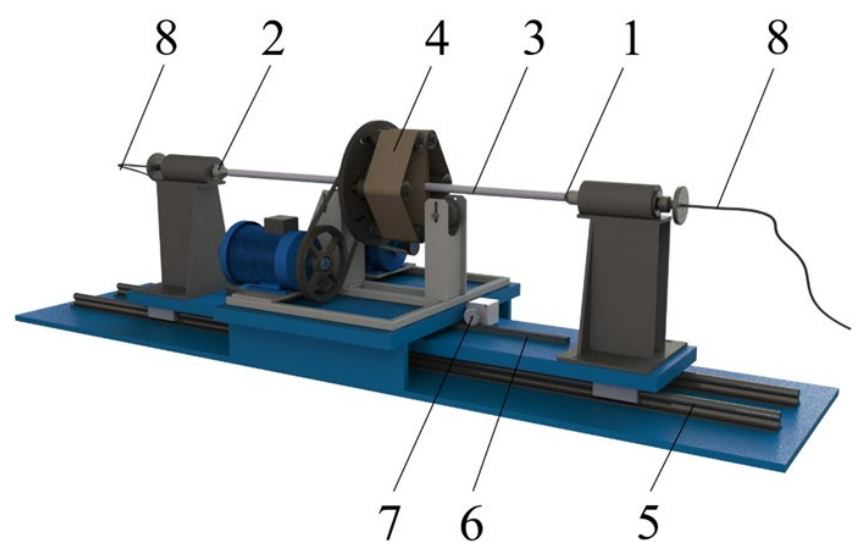

Fig. 3. Installation scheme for measuring cutting forces: 1, 2 - front and rear tendometric centers, respectively; 3 - workpiece; 4 - installation for rotational belt grinding; 5 - guides to the mills; 6 - toothed rack; 7 - is a step-by-step electric motor; 8 - wires leading to the device to measure the forces of cutting. 
According to the analysis of the literature data [15], to simulate the values of the cutting force component $P_{z}$ from variable factors: the radial component of the cutting force $-P_{y}$, the speed of the tape $-V_{l}$ and the grain of the abrasive tape $-X_{H}$ a regression dependence of the power form was adopted:

$$
P_{z}=C_{P z} \cdot P_{y}^{\alpha_{1}} \cdot V_{l}^{\alpha_{2}} \cdot X_{H}^{\alpha_{3}}
$$

where $C_{P z}$ - coefficient of proportionality; $P_{y}$ - radial component of cutting force; $V_{l}-$ belt speed; $X_{H}$ - abrasive tape grain; $\alpha_{1}, \alpha_{2}, \alpha_{3}$ - degree indices.

After taking the logarithm this equation 1 takes the form:

$$
\ln P_{z}=\ln C+\ln P_{y}+\ln V_{l}+\ln X_{H} .
$$

Testing the adequacy hypothesis of the linear model when expressing the results of the experiment is carried out using a polynomial:

$$
y=b_{0}+b_{1} x_{1}+b_{2} x_{2}+b_{3} x_{3}
$$

where $y-$ is $\ln P_{z} ; x_{1}, x_{2}, x_{3}$ - coded values of factors; $b_{1}, b_{2}, b_{3}$ - coefficients of model parameters; $b_{0}$ - free term.

The encoded values of the factors were determined by the expression:

$$
x_{i}=\frac{2\left(\ln \breve{x}_{i}-\ln \breve{x}_{i}^{B}\right)}{\ln \breve{x}_{i}^{B}-\ln \breve{x}_{i}^{H}}+1,
$$

where $x_{i}-$ is the coded value of the $\mathrm{i}$-th factor; $\breve{x}_{i}-$ is the natural value of the $\mathrm{i}$-th factor; $\breve{x}_{i}^{\beta}-$ is the natural value of the upper level of the i-th factor; $\breve{x}_{i}^{H}-$ is the natural value of the lower level of the i-th factor.

The accepted factor levels are shown in Table 1.

As a result of statistical processing of experimental data, the dependence of the tangential component of the cutting force on the speed of movement of the belt, its grain and the radial component of the cutting force is obtained:

$$
P_{z}=14,48 \cdot P_{y}^{0,406} \cdot V_{l}^{0,04} \cdot X_{H}^{-0,612} .
$$

Experimental studies and statistical processing are summarized in table 1.

Figures 4, 5 illustrate the variation of the force $P_{z}$ from the above parameters. 
Table 1. Values of variability interval and results of processing of data on investigation of tangential force of cutting of rod from material D 16

\begin{tabular}{|c|c|c|c|c|c|c|c|c|c|c|c|c|c|c|c|}
\hline \multicolumn{6}{|c|}{ Controlled variables } & \multicolumn{2}{|c|}{$P_{y}[\mathrm{~N}]$} & \multicolumn{2}{|c|}{$\begin{array}{c}V_{l} \\
{[\mathrm{~m} / \mathrm{s}]}\end{array}$} & $X_{H}$ & \multicolumn{5}{|c|}{ Approximating constraint } \\
\hline \multicolumn{6}{|c|}{ Top Level } & \multicolumn{2}{|c|}{40} & \multicolumn{2}{|c|}{20} & 40 & \multirow{4}{*}{\multicolumn{5}{|c|}{$\begin{array}{c}\ln P_{z}=2,673+0,406 \ln P_{y}+0,04 \ln V_{l}-0,612 \ln X_{H} \\
P_{z}=14,48 \cdot P_{y}^{0,406} \cdot V_{l}^{0,04} \cdot X_{H}{ }^{-0,612}\end{array}$}} \\
\hline \multicolumn{6}{|c|}{ Lower level } & \multicolumn{2}{|c|}{15} & \multicolumn{2}{|c|}{10} & 10 & & & & & \\
\hline \multicolumn{6}{|c|}{ Main level } & \multicolumn{2}{|c|}{27,5} & \multicolumn{2}{|c|}{15} & 25 & & & & & \\
\hline \multicolumn{6}{|c|}{ Variation interval } & \multicolumn{2}{|c|}{12,5} & \multicolumn{2}{|c|}{5} & 15 & & & & & \\
\hline \multicolumn{5}{|c|}{$\begin{array}{c}\text { Experiment } \\
\text { planning matrix }\end{array}$} & \multirow{2}{*}{\multicolumn{7}{|c|}{$\begin{array}{c}\text { Results of the experiment and variance of } \\
\text { deviations }\end{array}$}} & \multirow{2}{*}{\multicolumn{2}{|c|}{$\begin{array}{l}\text { Check of } \\
\text { homogeneity of } \\
\text { dispersions }\end{array}$}} & \multirow{2}{*}{\multicolumn{2}{|c|}{ Adequacy check }} \\
\hline \multirow{2}{*}{$\begin{array}{c}\text { № } \\
\text { point }\end{array}$} & \multicolumn{4}{|c|}{$\begin{array}{l}\text { Controlled } \\
\text { parameters }\end{array}$} & & & & & & & & & & & \\
\hline & $x_{0}$ & $x_{1}$ & $x_{2}$ & $x_{3}$ & $y_{1}$ & $y_{2}$ & $y_{3}$ & $y_{4}$ & $y_{5}$ & $\bar{y}$ & $S_{v}^{2}$ & $\sum_{v=1}^{N} S_{v}^{2}$ & 0,0104 & $\sum_{V=1}^{N}\left(\bar{y}_{V}-y_{V}\right)^{2}$ & $7,72 \cdot 10^{-6}$ \\
\hline 1 & + & + & + & + & 1,98 & 2,0 & 1 & 1,94 & 1,97 & 1,97 & $6,37 \cdot 10^{-4}$ & $S_{v \max }^{2}$ & 0,0029 & $S_{\text {ad }}^{2}$ & $9,65 \cdot 10^{-6}$ \\
\hline 2 & + & - & + & + & 1,58 & 1,6 & $5 \mid 1,5$ & 1,53 & 1,61 & 1,58 & $2,87 \cdot 10^{-3}$ & $G$ & 0,3185 & $F$ & $7,46 \cdot 10^{-3}$ \\
\hline 3 & + & + & - & + & 1,96 & 1,9 & $3 \mid 1,9$ & 1,97 & 1,91 & 1,94 & $6,02 \cdot 10^{-4}$ & $q[\%]$ & 5 & $q_{\mathrm{ad}}[\%]$ & 5 \\
\hline 4 & + & - & - & + & 1,53 & 1,5 & $1,1,5^{\circ}$ & 1,62 & 1,53 & 1,55 & $1,83 \cdot 10^{-3}$ & $V_{1 \mathrm{~B}}$ & 4 & $V_{\text {1ad }}$ & 4 \\
\hline 5 & + & + & + & - & 2,86 & 2,8 & 32,8 & 2,81 & 2,88 & 2,85 & $9,38 \cdot 10^{-4}$ & $V_{2 \mathrm{~B}}$ & 8 & $V_{\text {2ad }}$ & 32 \\
\hline 6 & + & - & + & - & 2,44 & 2,4 & 92,4 & 2,49 & 2,41 & 2,45 & $1,48 \cdot 10^{-3}$ & $G_{\mathrm{cr}}$ & 0,3185 & $F_{\mathrm{cr}}$ & 2,69 \\
\hline 7 & + & + & - & - & 2,82 & 2,8 & $12,7^{\prime}$ & 2,86 & 2,85 & 2,82 & $1,26 \cdot 10^{-3}$ & \multirow{2}{*}{ Conclusion } & \multirow{2}{*}{$G<G_{\mathrm{cr}}$} & \multirow{2}{*}{ Conclusion } & \multirow{2}{*}{$F<F_{\text {cr }}$} \\
\hline 8 & + & - & - & - & 2,45 & 2,3 & 92,3 & 2,43 & 2,45 & 2,42 & $7,43 \cdot 10^{-4}$ & & & & \\
\hline \multirow{3}{*}{ 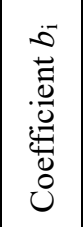 } & \multirow{3}{*}{$\begin{array}{l}\stackrel{2}{\sigma} \\
\therefore\end{array}$} & \multirow{3}{*}{$\frac{2}{0}$} & \multirow{3}{*}{$\frac{1}{0}$} & \multirow{3}{*}{ 官 } & & & & & heckin & ng the & significance & e of coeffici & ents & & \\
\hline & & & & & $S^{2}\{b$ & & $S\left\{b_{i}\right\}$ & $\begin{array}{c}q \\
\%\end{array}$ & $V_{3 \mathrm{H}}$ & $t_{\mathrm{cr}}$ & $t_{\mathrm{o}}$ & $t_{1}$ & $t_{2}$ & $t_{3}$ & $\begin{array}{l}\text { All } \\
\text { coefficients }\end{array}$ \\
\hline & & & & & $\begin{array}{r}3,24 . \\
5\end{array}$ & & $\begin{array}{l}69 \cdot 10 \\
3\end{array}$ & 5 & 32 & 2,036 & 386,45 & 34,89 & 2,5 & $-76,82$ & $\begin{array}{c}\text { are } \\
\text { significant }\end{array}$ \\
\hline
\end{tabular}

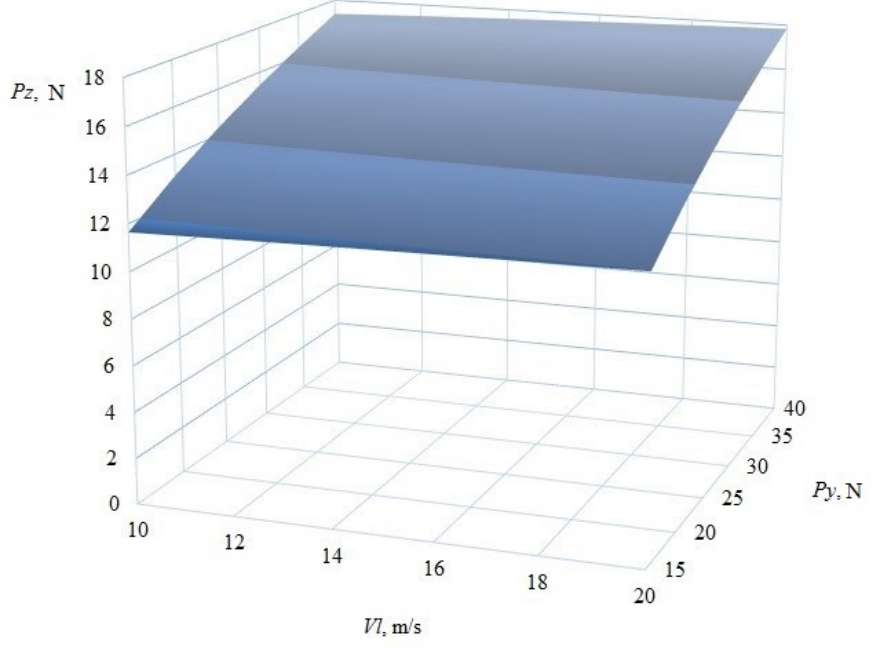

Fig. 4. Effect of radial component of cutting force and cutting speed on tangential component of cutting force during treatment of D 16 material by abrasive tape with grain 10. 


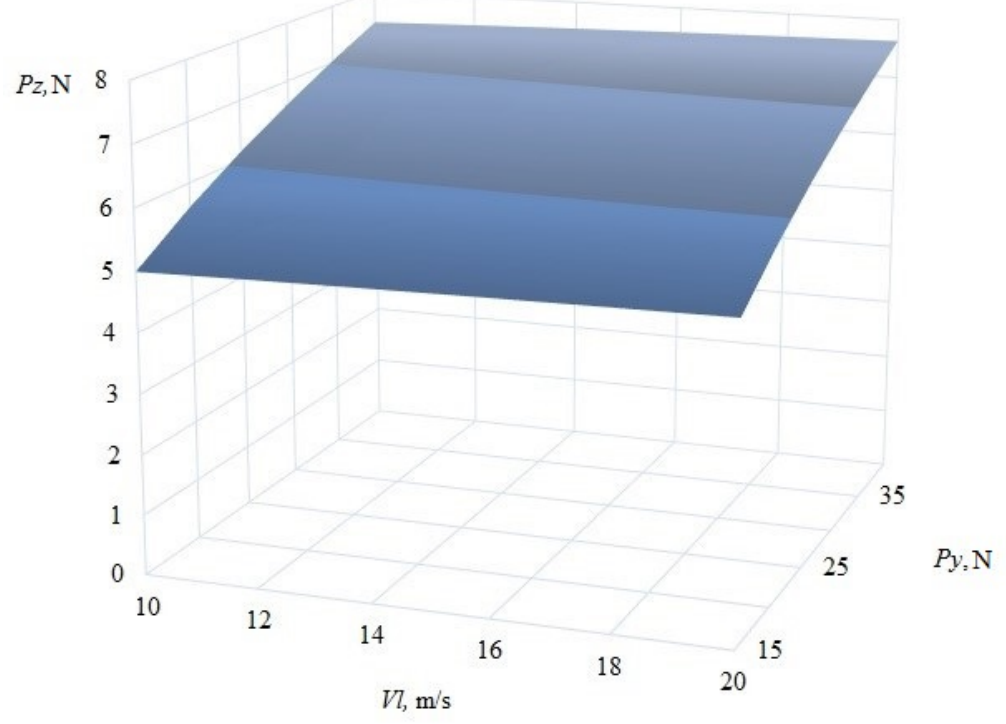

Fig. 5. Effect of radial component of cutting force and cutting speed on tangential component of cutting force during treatment of D 16 material by abrasive tape with grain 40.

\section{Conclusions}

The obtained dependence makes it possible to differentiate the effect of the belt speed, its grain size, and radial component of the cutting force on the tangential component of the cutting force and to judge the state of the tape rotary grinding process.

\section{References}

[1] S. Bratan, P. Novikov, S. Roshchupkin, Application of Combined Taps for Increasing the Shaping Accuracy of the Internal Threads in Aluminium Alloys, Procedia Engineering. 150 (2016) 802-808. https://doi.org/10.1016/j.proeng.2016.07.115

[2] S.M. Bratan, S.I. Roshchupkin, A.O. Kharchenko, A.S. Chasovitina, Probabilistic model of surface layer removal during grinding of brittle non-metallic materials, Metal processing (technology, equipment, tools). 23 No. 2 (2021) 6-16. (in Russ.). https://doi.org/10.17212/19946309-2021-23.2-6-16

[3] S.M. Bratan, S.I. Roshchupkin, A.O. Kharchenko, A.S., Chachavitina Simulation of allowance removal in the contact area during internal grinding of brittle non-metallic materials, Metal processing (technology, equipment, tools). 23 No. 2 (2021) 31-39. (in Russ.). https://doi.org/10.17212/1994-6309-2021-23.2-31-39

[4] S. Bratan, T. Stadnik, S. Roshchupkin, Investigation of the mechanism of interaction of cutting fluids with the material of the workpiece when grinding titanium parts in the presence of inorganic salt, Materials Today: Proceedings. 38 (2021) 2048-2051.

https://doi.org/10.1016/j.matpr.2020.10.135

[5] A. Chasovitina, S. Bratan, S. Roshchupkin, The cutting emulsions for grinding ceramics and sitall parts, Materials Today: Proceedings. 38 (2021) 2083-2087.

https://doi.org/10.1016/j.matpr.2020.10.153 
[6] A. Kharchenko, A. Chasovitina, S. Bratan, Modeling of regularities of change in profile sizes and wear areas of abrasive wheel grains during grinding, Materials Today: Proceedings. 38 (2021) 2088-2091. https://doi.org/10.1016/j.matpr.2020.10.154

[7] S.M. Bratan, Influence of the tool working surface state on evaluation of the forming filter parameters, IOP Conference Series: Materials Science and Engineering. 709(2) (2020) 022009. https://doi.org/10.1088/1757-899X/709/2/022009

[8] S. Bratan, B. Bogutsky, S. Roshchupkin, Development of mathematical model of material removal calculation for combined grinding process, Lecture Notes in Mechanical Engineering. 9783319956299 (2019) 1759-1769. https://doi.org/10.1007/978-3-319-95630-5_189

[9] S. Bratan, E. Vladetskaya, Flat grinding model, considering internal dynamics of the process MATEC Web of Conferences. 224 (2018) 01002. https://doi.org/10.1051/matecconf/201822401002

[10] S. Bratan, S. Roshchupkin, Synthesis of lunberger stochastic observer for estimation of the grinding operation state, MATEC Web of Conferences. 224 (2018) 01133. https://doi.org/10.1051/matecconf/201822401133

[11] S.M. Bratan, T.V. Stadnik, A.G. Kolesov, Balance of movements in the technological system with belt rotary grinding, News of Tula State University, Technical Sciences, Issue 8, Part 1, Tula State University Publishing House, Tula, 2017, pp. 270-275. (in Russ.)

[12] S. Bratan, A. Kolesov, S. Roshchupkin, T. Stadnik, Theoretical-probabilistic model of the rotary belt grinding process, MATEC Web of Conferences. 129 (2017) 01078. https://doi.org/10.1051/matecconf/201712901078

[13] S. Bratan, T. Stadnik, V. Golovin, Evaluation of effectiveness of cutting fluids for belt grinding of long-length products of titanium alloys, Materials Today: Proceedings. 38 (2021) 2013-2018. https://doi.org/10.1016/j.matpr.2020.10.031

[14] S.A. Shilyaev, Development of a rotary belt grinding device to ensure accuracy of parts in assembly production, Assembly in mechanical engineering, instrument making. 3 (2008) 25-27. (in Russ.)

[15] S.A. Shilyayev Investigation of technological parameters of process of rotary belt grinding and obtaining mathematical relationships for quantitative analysis of cutting conditions, Izhevsk State Technical University Reporter. 2 (38) 2008 23-26. (in Russ.) 